\title{
Residential Mobility in Older Dutch Adults: Influence of Later Life Events
}

\author{
By Brigitte Bloem, Theo Van Tilburg \& Fleur Thomése
}

\begin{abstract}
In this study, we examined life course events of older Dutch adults in relation to three types of moves and the moving distance. Using the frameworks developed by Litwak and Longino (1987) and Mulder and Hooimeijer (1999), we stipulated life events or triggers and conditions in various life domains. We selected a total of 1160 men and 1321 women (aged 54 to 91) from the Longitudinal Aging Study Amsterdam. We conducted multinomial logistic regression analyses to predict moves to a residential care facility, adapted housing or regular housing and to predict the moving distance. Retirement, an empty nest, widowhood and a decline in health each triggered specific moves. In additional analyses, the effects of triggers, especially health changes, were moderated by conditions. There is no indication of a specific trajectory of moves associated with consecutive life events, as suggested by Litwak and Longino. By combining triggers and conditions, however, the framework developed by Mulder and Hooimeijer allows for a more valid analysis.
\end{abstract}

Keywords: residential mobility, older adults, longitudinal, life course events.

Brigitte Bloem, Theo van Tilburg \& Fleur Thomése. Department of Sociology, VU University Amsterdam, The Netherlands. 
International Journal of Ageing and Later Life

\section{Introduction}

Moves are recognized as influential life course events. They often occur in the context of other life events, such as job, marital status or family size changes (Schachter 2001). The life events and other conditions in people's lives put demands on their future housing. For example, getting married and having children often trigger a need for more space (Clark \& Huang 2003). The purpose of the present study is to explore how events in later life contribute to various types of moves in older Dutch adults. Although distinctive types of moves, such as retirement migration or institutionalization, have been researched in a life course context, a broader theoretical and empirical understanding of the trajectories in later life leading to various residential moves is called for.

Research into later-life migration often starts from the life course framework developed by Litwak and Longino (1987), which has distinguished three types of moves following various events in the lives of older people, i.e. retirement moves to a nicer environment after parental or economic duties decrease, comfort moves, often to the vicinity of children in the face of moderate disabilities, and care moves to a residential care facility due to chronic disabilities. Each type is thought to occur at a successive point in the life course. An attractive feature of this framework is its linkage between life events and specific types of moves. The path to residential mobility can, however, be conceivably more complex than the framework suggests. People may go through a broader range of life events in various life domains (Elder 1985). This makes simple associations between specific events and moves less likely.

The framework of residential mobility in the life course developed in the Netherlands by Mulder and Hooimeijer (1999) may help differentiate the effects of life events on residential mobility. It has distinguished between triggers and conditions of moving and, like the Litwak and Longino framework, departs from a life course perspective, but assumes an interdependency between various life course domains. It has differentiated between triggers and conditions that may occur in these life domains. A change in one domain can trigger a move. Conditions in other domains may stimulate or restrict the actual move. We distinguished the domains of employment, family, health and the home. 


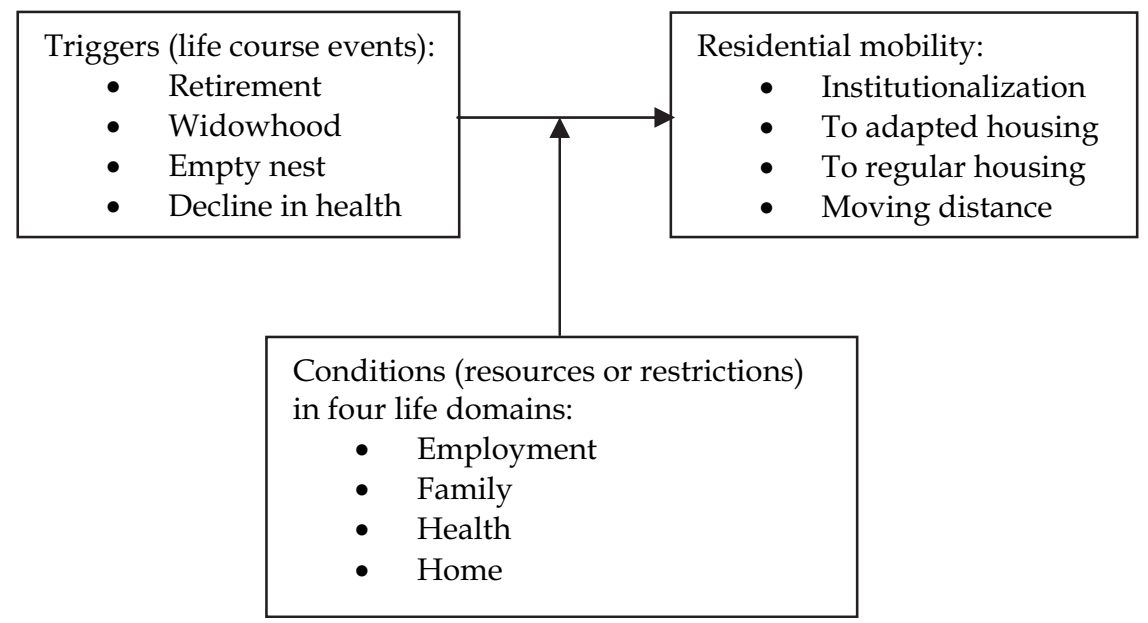

Figure 1. Theoretical framework of residential mobility in the life course.

For example, retirement can be seen as a change in the employment domain that may trigger a desire to move to an attractive environment. Whether one actually moves depends on circumstances such as income level or the proximity of children that condition the action of the individual. Residential mobility may be triggered by events in several domains, such as employment and health, resulting in multidimensional trajectories to residential mobility. There is no fundamental classification of triggers and conditions. For example, retirement may serve as a trigger to consider moving in one case, and as a condition in another case, if moving closer to the children is postponed because one of the parents is still working. The model indicates that the effects of triggers or changes in certain life domains on residential moves are moderated by conditions in other life domains.

Our theoretical discussion has led to two research questions: (1) What triggers in various life domains affect the probability of moves as distinguished by Litwak and Longino (1987)? (2) Is there an accumulation of triggers and conditions in one or more life domains that affects the probability of a specific move? 
International Journal of Ageing and Later Life

Litwak and Longino (1987) have based their classification of moves on the underlying motives (leisure, support and care) as well as the distance to the new location. Since the motives underlying a move are closely related to the triggers, we classified the moves via objective characteristics of the housing at the old and new sites. We distinguished moves to residential care facilities (institutionalization), moves to adapted housing and moves to regular housing. At residential care facilities, care is provided by professionals in a sheltered environment. At adapted housing, homes in the community are equipped with special adaptations. Older adults are expected to move there in the event of an increased need for support or care, a decline in health or a lack of help from children in the immediate vicinity. Older people who move to regular housing without any special provisions for the elderly or the disabled may have various reasons for doing so, such as leisure activities and wanting to be near their children. In addition to housing characteristics, we classified moves by distance, i.e. in the neighborhood, outside the neighborhood but in the town, and outside the town.

We selected triggers in three life domains. In the employment domain, we identified retirement as a trigger. In the family domain, we identified the last child leaving home and widowhood as triggers. Although the importance of wanting to be near the children is generally acknowledged, very little attention has been devoted to its effects on moving (Walters 2002). Some researchers show that children who live nearby act as a constraint on moving (de Jong et al. 1995), but we have not found any research on the effect of children leaving home. In the health domain, a decline in health acted as a trigger.

Conditions were selected in four life domains that can serve as triggers in similar or different life domains. We conceived them as resources or restrictions related to the triggers. For example, having children nearby might be a different conditioning situation for individuals in poor health than having children far away, since children living nearby can be of assistance. In the employment domain, the influence of income was addressed. In the family domain, we included the presence of a spouse as a conditioning situation. We also included having children or not, and the distance to the child living nearest. In the health domain, we considered the health status and age of the older adult. The home domain included 
physical characteristics of the home, home ownership, the attractiveness of the environment and the degree of urbanization as conditions. We generally assume that less favorable conditions promote residential mobility. Retired people, for example, may move to a nicer area to improve their living environment.

Before turning to our empirical sections, we should note that the Dutch housing market is characterized by low mobility. The annual percentage of movers is around $10 \%$ of all the households in 2000-2005 (Statistics Netherlands 2007), as compared to $12 \%$ in the UK and $14 \%$ in the USA (Census, Office of National Statistics 2001; U.S. Census Bureau 2006). For older movers, the mobility rates are considerably lower and only $1 \%$ of Dutch adults above the age of 50 move as compared to 5\% in the USA and around $4 \%$ in the UK. One reason for the low mobility is that the Netherlands has a relatively large amount of affordable rental housing for middle-income as well as low-income households. Data of Census, Office of National Statistics (n.d.) across the European Union for 2000 show that in the Netherlands, the percentage of owner-occupied housing (53\%) is low compared to the UK $(71 \%)$ and the USA (66\%, U.S. Census Bureau 2000). This probably serves to limit mobility. In addition, it is the aim of Dutch care policy to stimulate people to live independently as long as possible. The Dutch government subsidizes home adaptations as well as formal care, stimulating older Dutch adults to postpone moving to residential care facilities. The lengthy assessment procedures for residential care and long waiting lists also delay the actual move to a care facility.

\section{Method}

\section{Respondents}

Data were derived from the Longitudinal Aging Study Amsterdam (LASA), an ongoing longitudinal, multidisciplinary research project focused on a wide range of topics related to the physical and cognitive health, and social and psychological functioning of the aging population (Deeg et al. 1993). This program used a stratified random sample of men and women born from 1908 to 1937. The oldest participants, particularly the oldest men, were over-represented in the sample. The sample was 
International Journal of Ageing and Later Life

taken from the population registers of eleven towns, varying in religion and urbanization. The LASA sample was initially recruited for the Living Arrangements and Social Networks (LSN) of Older Adults research program (Knipscheer et al. 1995). Of the 6107 eligible individuals in the LSN sample (T0), 2302 (38\%) were unwilling to participate due to a lack of interest or time; another 734 had died or were too ill or cognitively impaired to be interviewed. A total of 3107 LSN sample respondents took part in the first (T1) LASA cycle (1992/1993). In 1995-1996 (T2, $n=2545), 1998-1999$ (T3, $n=2076)$ and 2001-2002 (T4, $n=1691)$ follow-ups were conducted. After T1, $1051(34 \%)$ respondents had died, $222(7 \%)$ refused to cooperate and $143(5 \%)$ were ineligible or not contacted. The intervals between the observations were an average of 3.0 years $(\mathrm{SD}=0.3)$ and the interval between T1 and T4 ranged from 8.2 to 9.9 years $(n=1674, \mathrm{M}=9.0, \mathrm{SD}=$ $0.2)$.

In this study, we confined ourselves to respondents living independently at T1 with at least one follow-up observation available $(n=2481)$. From this sample, 58 respondents who were institutionalized and six who lived at a monastery are excluded. For 734 respondents data were partially missing at one or more observations. Most of them were too physically or cognitively weak to be interviewed with the full questionnaire. At T1, the 1160 males and 1321 females were between the ages of 55 and $86(\mathrm{M}=$ $69.5, \mathrm{SD}=8.5$ ). Of these respondents, $65 \%$ were married and $24 \%$ widowed.

\section{Instruments}

Types of Moves

Based on the respondent's address, we could tell at each observation whether a respondent had moved in the previous three years. The interviewer could classify the type of housing as regular housing (e.g. attached row, detached, apartment building), housing adapted for older adults (e.g. apartment building with services, housing near an institution including services provided by the institution) or an institution (residential or nursing home). Several types of moves were derived from this information, i.e. from regular to other regular housing, from regular to adapted housing and from regular or adapted housing to an institution. A second 
categorization was based on the distance of the move, i.e. in the neighborhood, outside the neighborhood but in the town (an average of $2.5 \mathrm{~km}$ ), outside the town but in the country (an average of $42.3 \mathrm{~km}$, with a maximum of $244 \mathrm{~km}$ ) and abroad. The distance of the move was measured by the postal code and town boundaries; using only one of them would give a biased view, since both vary in size.

\section{Triggers}

At each observation, the respondents were asked whether they had a paying job, children living in the household and a spouse. With regard to the job, the children in the household and marital status, an altered situation at the follow-up was considered a life event or trigger.

We considered five aspects of health, which included objective and subjective indicators. The five aspects were covered in six questions about difficulty performing activities of daily living (ADL) such as "Can you walk up and down stairs?" The possible answers were not at all, only with help, with a great deal of difficulty, with some difficulty and without difficulty. The sum-score indicated the ADL capacity (reliability $\alpha=0.87$ ).

A direct question assessed the individual's health related to limitations in functioning: "Are you restricted in your activities of daily living due to chronic illnesses, health disorders or handicaps?" The possible answers were no limitations, slight limitations and severe limitations.

Subjective health was assessed by asking "How is your health in general?" The possible answers were poor, not so good, fair, good and very good. Respondents could fill in any of seven chronic diseases, i.e. pulmonary disease, cardiac disease, arteriosclerosis, stroke, diabetes, arthritis and malignant neoplasm. Cognitive functioning was assessed using the Mini Mental State Examination (MMSE; Folstein et al. 1975). We constructed one composite variable for health, because we were not interested in the five specific aspects of health. A decline in health between two observations as a trigger was considered significant if the score on any of the five health aspects was poorer at the second observation and the difference from the first observation was more than one standard deviation. Since there were few respondents with a decline in more than three health aspects, we condensed decline scores of three or more points into one category of a severe decline in health. The other categories included a moderate (two 
International Journal of Ageing and Later Life

points difference) or slight decline in health (one point difference) and stability.

Based on these questions, we defined the following triggers: retirement, an empty nest, widowhood and a decline in health.

In accordance with the definition in the Introduction, we categorized conditions under four life domains: employment, family, health and home.

\section{Employment}

We considered income a condition related to the domain of employment. Net household income was divided into twelve classes. Missing values $(6 \%)$ were replaced by the mean income in the neighborhood based on data provided by Statistics Netherlands. A monthly income of 800 euros or less was considered a low income.

Family

One of the variables indicated if the respondent has children. If so, the amount of time it takes to travel to each child using whatever transportation the respondent usually uses is the assessed travel time between parents and children. Travel time to the nearest child was determined and dichotomized as within ten minutes, excluding children living in the household and at a distance over ten minutes. Another variable assessed the presence of a spouse in the household.

Health

Unlike a decline in health as a trigger, we defined health status as a condition moderating the effects of other triggers. Based on the composite variable described above, health status as a condition was categorized as severe health problems ( $4 \%$ of the respondents had a score more than one standard deviation below the mean for three or more aspects), moderate health problems (two aspects, 9\%), slight health problems (one aspect, $25 \%$ ) or no health problems, i.e. no downward deviation on any health aspect $(62 \%)$. Lastly, we interpreted age as an indicator in the life domain of health as well.

Home

The interviewer observed the accessibility of the home, i.e. with a ground floor entrance, or elevator access or an entrance via stairs. The extent of home adaptations was assessed, e.g. extra handrails or adaptations in the 
kitchen, bedroom or bathroom. One variable pertained to home ownership. The percentage of recreational and nature areas in the town affected the attractiveness of the environment. The level of urbanization of the neighborhood was divided into five classes, ranging from not urban (less than 500 addresses per square kilometer) to highly urban (more than 2500 addresses). The data were derived from a database provided by Statistics Netherlands (den Dulk et al. 1992). A factor score derived from the mean household income, the percentage of households with a low income, the percentage of unemployed people and the percentage of households with a poor educational level indicated the social status of the neighborhood. This factor score was derived from a database provided by a commercial firm.

\section{Procedure}

To facilitate the statistical analysis, we accumulated the data of longitudinal observations and selected 710 respondents who moved between $\mathrm{T} 1$ and $\mathrm{T} 2$, between $\mathrm{T} 2$ and $\mathrm{T} 3$ (if not between $\mathrm{T} 1$ and $\mathrm{T} 2$ ), and between $\mathrm{T} 3$ and T4. Matching each respondent who moved with non-movers enhanced the study of the determinants of moving. For each moving respondent, we needed non-movers from the same observation interval for comparison. Matching non-movers was considered successful if respondents were observed at a minimum of two consecutive waves, if these observations were made at the same waves as for the mover, if they had not moved during any of the observations, if they had the same gender as the mover and if the absolute age difference with the mover was no more than five years. To obtain as much variance in the sample of non-movers as possible, we looked for two matching non-movers. A first match was available for all the movers, a second one failed for 59 older women who were institutionalized and another 19 women. The sample of matched nonmovers included 1342 respondents. The matching procedure yielded subsamples of movers and non-movers that did not differ in gender composition $\left(\chi_{(1)}^{2}=1.1, p>0.05\right)$ and average age $(\mathrm{M}=73.3$ for movers and $\mathrm{M}=72.5$ for non-movers, $\left.t_{(2050)}=1.9, p>0.05\right)$.

To answer the first research question, we conducted a multinomial logistic regression analysis of the three types of moves on each trigger, controlled for gender and age. The aim of this analysis was to determine whether triggers and relocation coincided in the same observation period. 
International Journal of Ageing and Later Life

The triggers were retirement, an empty nest, widowhood and a decline in health. Not having moved and not having experienced a life event were both categories of reference. The Wald statistic, which is $\chi^{2}$ distributed, evaluated the significance of a predictor. The odds ratio (OR) expressed the effect of a specific predictor, which is positive if OR $>1$, negative if OR $<1$, and there is no effect if $\mathrm{OR}=1$.

As regards the second research question, we addressed whether an accumulation of triggers and conditions affected the probability of a specific move, and examined the effects of conditions separately for each trigger. Each of the analyses was restricted to older adults who had experienced a trigger related to the specific type of move. For example, we examined which conditions contributed to the retired respondents moving to regular housing. We conducted eight of the twelve possible logistic regression analyses (four triggers $\times$ three types of moves). The other four combinations of triggers and moves included too few respondents. We used a stepwise procedure because of the large number of explanatory variables in relation to the number of respondents. For the same reason, we only included the variable added first to the equation $(p<0.05)$. Conditions included the respondent characteristics (income in the employment domain; children, traveling time to closest child and marital status in the family domain; health and age in the health domain; gender), home characteristics (accessibility, adjustments and tenure) and neighborhood characteristics (attractiveness of the environment, urbanization and social status) in the home domain, all measured at the pre-move observation for movers and at the first selected observation for non-movers.

\section{Results}

Of the 2481 respondents, $89 \%$ lived in a regular home and $11 \%$ in adapted housing at T1. Before turning to the research questions, we describe the moves in greater detail. The results showed that older Dutch adults did not move frequently. In the nine years from T1 to T4, 739 (30\%) respondents moved, 107 of them more than once. Except for 41 who stayed in the same type of housing, most of the multiple movers changed the type of housing. Eight multiple movers went from a regular home via adapted housing to institutionalization. At each observation, about $13 \%$ had moved once or 
Table 1. Number of older adults who moved $(n=2481)$

\begin{tabular}{|c|c|c|c|c|c|c|}
\hline & \multicolumn{2}{|c|}{$\mathrm{T} 1-\mathrm{T} 2$} & \multicolumn{2}{|c|}{$\mathrm{T} 2-\mathrm{T} 3$} & \multicolumn{2}{|c|}{$\mathrm{T} 3-\mathrm{T} 4$} \\
\hline & Abs. & $\%$ & Abs. & $\%$ & Abs. & $\%$ \\
\hline Did not move & 2157 & 87 & 1770 & 87 & 1457 & 87 \\
\hline \multicolumn{7}{|l|}{ Moved, according to type of move } \\
\hline Institutionalization & 80 & 3 & 77 & 4 & 70 & 4 \\
\hline From regular to adapted housing & 84 & 3 & 52 & 3 & 39 & 2 \\
\hline From regular to regular housing & 147 & 6 & 122 & 6 & 84 & 5 \\
\hline Other move & 13 & 1 & 20 & 1 & 24 & 1 \\
\hline \multicolumn{7}{|l|}{$\begin{array}{l}\text { Moved and not institutionalized, according } \\
\text { to distance }\end{array}$} \\
\hline In the neighborhood & 95 & 4 & 66 & 3 & 55 & 3 \\
\hline Outside the neighborhood, in the town & 85 & 3 & 64 & 3 & 42 & 3 \\
\hline Outside the town, in the Netherlands & 62 & 2 & 63 & 3 & 34 & 2 \\
\hline Outside the Netherlands & 2 & 0 & 1 & 0 & 2 & 0 \\
\hline Deceased & & & 319 & - & 633 & - \\
\hline No observation, otherwise & & & 121 & - & 174 & - \\
\hline
\end{tabular}

Multiple moves are included.

more in the previous three years (Table 1). Half the moves were to suitable housing for older adults: about $4 \%$ of the respondents were institutionalized and 3\% moved from regular to adapted housing. The others moved from regular to other regular housing $(6 \%)$ or made another move, for example from adapted housing to regular housing or to other adapted housing $(1 \%)$. Due to the small number, the latter category $(n=29)$ was not taken into account in further analyses. In the cases of the remaining movers $(n=710)$, the first move was taken into account (note that the number of movers was smaller than the row totals in Table 1 suggest). We studied 327 older adults who moved from regular housing to other regular housing, 170 who moved from regular to adapted housing, and 213 who moved from regular or adapted housing to be institutionalized.

The new homes of respondents who moved to regular housing $(n=327)$ more often had special adjustments, such as an adapted telephone or an alarm ( $2 \%$ as compared to $0 \%$ in their former homes), adaptations to the stairs (24\% as compared to $6 \%)$ and adaptations to the kitchen, bathroom 
International Journal of Ageing and Later Life

or bedroom (19\% as compared to $4 \%)$. Some sold their former home and rented their new one (14\%), others became homeowners (7\%). Differences between former and new homes were more pronounced in respondents who moved from regular to adapted housing $(n=170)$. Almost all of them now had a ground floor entrance or elevator access ( $99 \%$ as compared to $87 \%$ of their former homes). Moreover, there were more often home adjustments: adapted telephone or alarm ( $40 \%$ as compared to $1 \%)$, adaptations to the stairs (66\% as compared to $14 \%$ ) and adaptations to the kitchen, bathroom or bedroom ( $55 \%$ as compared to $13 \%$ ). Many sold their former home and now rented their new one $(29 \%)$. One respondent became a homeowner $(1 \%)$.

With regard to the moving distance, we excluded the institutionalized respondents $(n=213)$, as they have little choice in where they move to. Many moves from regular to other regular or adapted housing were local: $37 \%$ in the neighborhood, $34 \%$ to another often nearby neighborhood in the same town and $28 \%$ to outside the town $(n=497)$. Five respondents moved abroad.

The type of move was associated with the moving distance $(n=493$, $\left.\chi_{(2)}^{2}=24.4, p<0.001\right)$. Older adults who moved to adapted housing more often stayed in the neighborhood $(49 \%)$ and less frequently left the town $(15 \%)$, as compared to those who moved to regular housing. For this group, the results were reversed; they more often left the town $(35 \%)$ and less frequently stayed in the neighborhood (31\%).

In the cases of the respondents who had left the neighborhood $(n=308)$, the new neighborhood had a higher status $(M=55.6)$ than the old one $\left(\mathrm{M}=52.1, t_{(307)}=4.0, p<0.001\right)$. The degree of urbanization did not differ, nor did the attractiveness of the environment. Furthermore, older adults more often lived closer to a child after a move. Before leaving the neighborhood, 88 respondents lived close to a child, as did 108 after moving $\left(\chi_{(1)}^{2}=44.2, p<0.001\right)$. Of these movers, 32 had a child close by in the old neighborhood and not in the new one, and 52 were in the opposite situation.

In response to both research questions, we compared 710 movers and 1342 matched non-movers. Of the four selected life events or triggers that determined a specific move, a decline in health was most frequently observed. A moderate or severe decline in health was observed in $11 \%$ of 
the older adults: $3 \%$ were retired, $5 \%$ experienced an empty nest and $6 \%$ were widowed. Of the respondents, $60 \%$ had experienced no life event or only a small decline in health. The co-occurrence of these events was rare (4\%). The average age when life events occurred differed: the mean age at baseline of those who had retired was $63.8(\mathrm{SD}=7.7)$, of those with an empty nest $66.4(\mathrm{SD}=7.7)$, of those who were widowed $74.9(\mathrm{SD}=7.1)$ and of those with a decline in health $77.5(\mathrm{SD}=7.3)$.

With regard to the first research question, we examined which triggers in different life domains could be associated with the three types of moves. Table 2 shows that each of the selected life events was relevant to a specific move. Institutionalization was more likely to occur if there was a decline in health, an event that occurs more often late in life. The odds ratio for a onepoint decline in health was 1.51, indicating that older adults with the strongest decline in health are about three and a half times more likely to be institutionalized than those with unchanged health. In addition to a decline in health, an empty nest triggered institutionalization.

A move to adapted housing was more likely after the loss of a spouse. This type of move is characteristic of people at an advanced age. A move to other regular housing was more likely after retirement. The effects of all

Table 2. Multinomial logistic regression analysis of types of moves on life events in other life domains $(n=2052)$

\begin{tabular}{|c|c|c|c|c|c|c|}
\hline & \multicolumn{2}{|c|}{$\begin{array}{l}\text { Institutionalization } \\
\qquad(n=213)\end{array}$} & \multicolumn{2}{|c|}{$\begin{array}{l}\text { From regular to } \\
\text { adapted housing } \\
\qquad(n=70)\end{array}$} & \multicolumn{2}{|c|}{$\begin{array}{l}\text { From regular to } \\
\text { regular housing } \\
\quad(n=27)\end{array}$} \\
\hline & Wald & OR & Wald & OR & Wald & OR \\
\hline Age (54-91) & $136.7^{* * *}$ & 1.17 & $9.9^{* *}$ & 1.03 & $66.3^{* * *}$ & .93 \\
\hline Sex (male-female) & $11.7^{* * *}$ & 1.80 & 0.0 & 0.98 & 0.3 & 0.93 \\
\hline Retirement & 0.3 & 0.57 & 1.6 & 1.90 & $5.5^{*}$ & 2.05 \\
\hline Empty nest & $9.9^{* *}$ & 3.86 & 0.5 & 1.36 & 3.2 & 1.58 \\
\hline Widowhood & 1.8 & 1.48 & $4.2^{*}$ & 1.79 & 0.4 & 1.20 \\
\hline Decline in health $(0-3)$ & $33.0^{* * *}$ & 1.51 & 0.3 & 0.95 & 0.9 & 0.93 \\
\hline
\end{tabular}

${ }^{*} p<0.05,{ }^{* *} p<0.01,{ }^{* * *} p<0.001$.

Did not move $(n=1342)$ and did not experience a life event are categories of reference. All the Wald statistics have one degree of freedom. 
International Journal of Ageing and Later Life

the triggers were controlled for age and gender differences. As is to be expected, the youngest older people are more likely to move to other regular housing and the oldest people and women are more likely to be institutionalized. The gender effect in institutionalization might apply to the oldest men, who more often live with a spouse than the older women.

The four triggers were related to the moving distance (Table 3). Retired people were more likely to move in the neighborhood as well as outside the town. After the last child left home, older adults predominantly moved in the neighborhood. The oldest ones were most likely to move in the neighborhood. Widowhood and a decline in health were not related to the moving distance.

The second research question addressed whether an accumulation of triggers and conditions affected the probability of a specific move. Table 4 provides an overview of the results of the logistic regression analyses. For four combinations of triggers and moves, the number of respondents was too small to conduct statistical analyses. For the remaining eight combinations, some samples were small due to the low prevalence of triggers. The first analysis pertained to the combination of retirement and

Table 3. Multinomial logistic regression analysis of distances of moves on life events in other life domains $(n=1472)$

\begin{tabular}{|c|c|c|c|c|c|c|}
\hline & \multicolumn{2}{|c|}{$\begin{array}{l}\text { In the } \\
\text { neighborhood } \\
(n=186)\end{array}$} & \multicolumn{2}{|c|}{$\begin{array}{l}\text { Outside the } \\
\text { neighborhood, in the } \\
\text { town }(n=168)\end{array}$} & \multicolumn{2}{|c|}{$\begin{array}{l}\text { Outside } \\
\text { the town } \\
(n=143)\end{array}$} \\
\hline & Wald & OR & Wald & OR & Wald & OR \\
\hline Age (54-91) & $8.1^{* *}$ & 1.03 & 3.5 & 1.02 & 3.1 & 0.98 \\
\hline Sex (male-female) & 0.5 & 1.12 & 0.3 & 1.10 & 0.0 & 0.99 \\
\hline Retirement & $7.4^{* *}$ & 3.00 & 1.5 & 1.81 & $7.5^{\star *}$ & 2.91 \\
\hline Empty nest & $15.6^{* * *}$ & 3.13 & 0.1 & 1.12 & 0.3 & 0.77 \\
\hline Widowhood & 1.9 & 1.53 & 0.4 & 1.26 & 0.7 & 1.36 \\
\hline Decline in health $(0-3)$ & 0.1 & 1.02 & 1.7 & 0.87 & 0.1 & 0.96 \\
\hline
\end{tabular}

${ }^{*} p<0.05,{ }^{* *} p<0.01,{ }^{* * *} p<0.001$

Institutionalized respondents $(n=213)$ and the matched non-movers $(n=367)$ are excluded. Did not move $(n=975)$ and did not experience a life event are categories of reference. All the Wald statistics have one degree of freedom. 
Residential Mobility in Older Dutch Adults

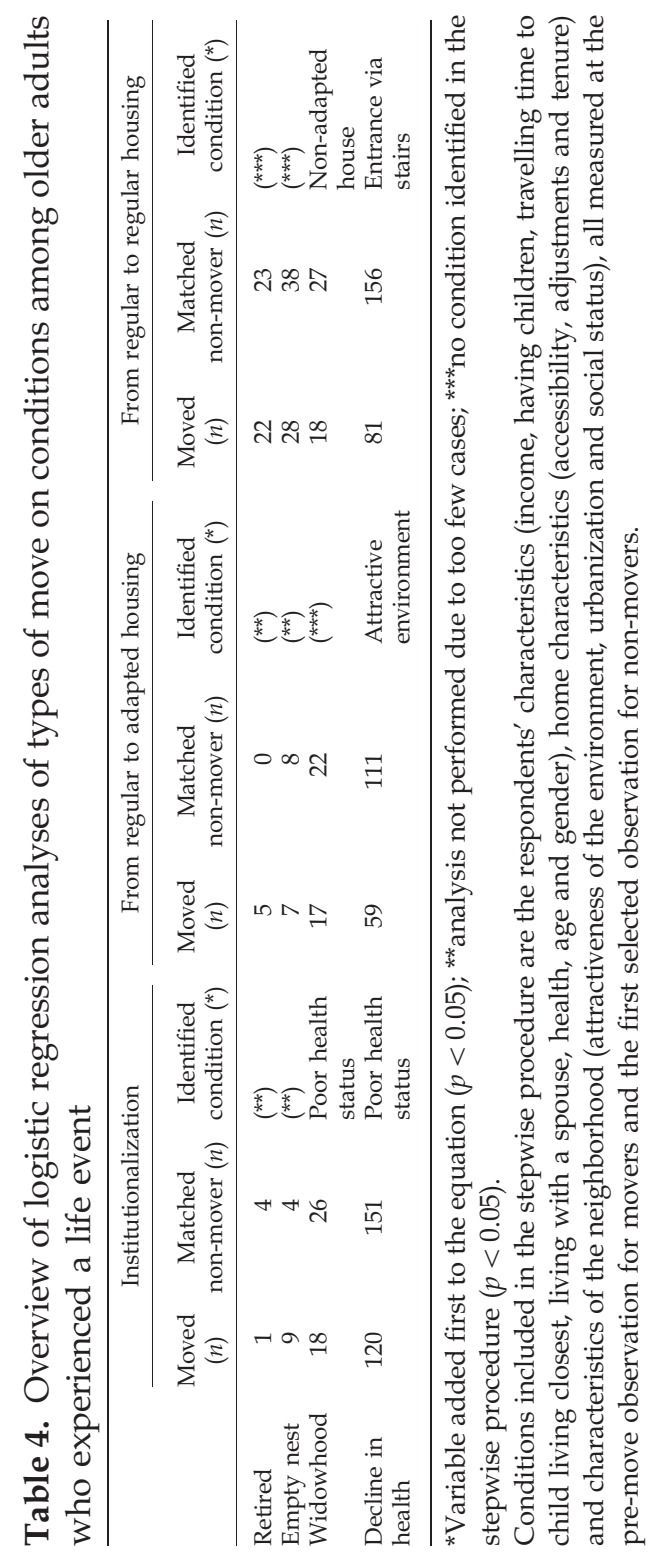


International Journal of Ageing and Later Life

moving from regular to other regular housing. As noted above, 327 respondents moved to regular housing, 22 of whom made a transition to retirement. Of the 647 non-moving respondents matched to respondents moving to regular housing, 23 made the transition to retirement. As shown in Table 4, the comparison of the 22 retired movers with the retired 23 nonmovers did not reveal conditions that increased the likelihood of moving to other regular housing.

No conditions were relevant in respondents who experienced the trigger of an empty nest. In those who were widowed, health problems at the premove observation $(\mathrm{OR}=2.25, p<0.01)$ did increase the likelihood of institutionalization. For example, a moderate health status, i.e. a score of more than one standard deviation below the mean for two health aspects, increased the likelihood of institutionalization by a factor of more than five compared to widows and widowers without health problems. We did not identify any condition that increased the likelihood of widows and widowers moving to adapted housing. Living in a house without adaptations, such as extra handrails, increased the likelihood of a move to other regular housing among widows and widowers ( $\mathrm{OR}=5.50, p<$ 0.05). In those who experienced the trigger of a decline in health, conditions were identified for all three types of moves. A poor health status at the pre-move observation increased the likelihood of institutionalization $(\mathrm{OR}=1.72, p<0.001)$. Living in an attractive environment increased the likelihood of a move to adapted housing (OR $=3.45, p<$ 0.05). Having an entrance to the house via a staircase increased the likelihood of a move to other regular housing $(\mathrm{OR}=3.12, p<0.05)$.

\section{Discussion}

Our purpose was to examine various kinds of moves by older Dutch adults from a life course perspective. We used the conceptual frameworks developed by Litwak and Longino (1987) and Mulder and Hooimeijer (1999) as our starting point to examine the impact of life events or triggers and conditions on residential mobility. The focus was mainly on moves to an institution, adapted housing and regular housing, and on moving distance. Triggers and conditions were defined in the life domains of employment, family, health and the home. Our first aim was to find out 
which triggers were related to specific moves. Subsequently, we studied the moderating effects of conditions.

Moves to residential care facilities were triggered by a decline in health, which is in accordance with the life course framework developed by Litwak and Longino (1987). Furthermore, the results showed that being older and having the last child leave home also increased the probability of institutionalization. These two additional factors are both indicative of the risk involved in living alone. In the case of health problems, the primary caregiver is most likely to be the spouse or children living in the household (Broese van Groenou \& van Tilburg 1997). Freedman (1996) and other researchers (Pot et al. 2001) have noted that married older people are about half as likely to be admitted to a nursing home as older people who live alone.

Health status had a conditioning effect on the likelihood of institutionalization after a life event. Widowed respondents and those experiencing a decline in health were more likely to be institutionalized if they already had health problems at our first observation. The first effect is the most striking, as we did not observe a direct effect of widowhood on the likelihood of institutionalization. The moderating effect of recurring health problems is indicative of the important role of informal caregivers in the household in avoiding institutionalization. It is less surprising that a decline in health increases the likelihood of being institutionalized in particular when the older adult has poor health. It may mean the decline in health is less important in predicting institutionalization than the current state of health. We used a broad indicator of health, which fits our purpose of studying the impact of important life changes on various moves. However, this may not be sufficient for an in-depth understanding of the factors involved in institutionalization. Most notably, admission procedures and waiting lists impact the occurrence and timing of institutionalization. We can conclude, however, that of the life domains, health is the main factor in institutionalization as a trigger and as a condition in combination with widowhood. The other domains were irrelevant to this type of move.

Moves to adapted housing were triggered by widowhood. We did not observe any moderating effects of conditions in combination with widowhood. Nor were there effects on the moving distance. This suggests 
International Journal of Ageing and Later Life

that having children available to provide support does not play a significant role in this type of move, even though moving to adapted housing clearly involves a greater need for support and care. In this sense, the model developed by Litwak and Longino (1987) cannot be confirmed. We did observe that older adults who live in an attractive environment were more likely to move to adapted housing after a decline in health. These areas are most typically in rural surroundings, which can mean more limited availability of specialized services and other assistance than in urban areas. This stimulates people to move earlier to adapted housing in or outside their region than if they can arrange more care and adaptations in their original home. This is in line with the return migration observed by Litwak and Longino (1987), insofar as health considerations stimulate a move away from recreational housing.

A move to regular housing had several triggers. Retirement triggered a move in one's own neighborhood as well as over a greater distance. In the first instance, the latter seems in line with the life course framework developed by Litwak and Longino (1987). Older adults indeed move to a neighborhood with a higher status, thus improving their living environment. However, there is no evidence that people move to more rural or attractive areas. Moves to attractive, rural areas have been observed in the Netherlands (Fokkema 1996; Thissen 1995; van der Molen 1993), but the rates are low. Only $6 \%$ of the people who moved from urban to rural areas in 2001-2002 were above 55 (WBO 2002). The distance from the Dutch coast on the west to the border on the east is about $150 \mathrm{~km}$, which takes about an hour and a half by car. The short distance may explain this low mobility. In the summer, many older adults remain for longer periods at caravan parks relatively close to their homes. A more common pattern for Europeans is also to spend part of the winter in Southern Europe without giving up their homes (Warnes et al. 2004). This may be perceived as a European variety of retirement moves observed in the USA and elsewhere, as older people seek out a better environment after retirement.

In addition to retirement, an empty nest could trigger a move, predominantly in the neighborhood. The most plausible explanation is that people move to a smaller house after their children leave home, but do not want to leave their familiar neighborhood. The proximity of children is not an important factor in choosing the new house, although we did note 
bivariate differences in moving distance related to the proximity of children. The small samples in the multivariate analyses only yielded the most robust effects. It is more interesting to note that the effects of a decline in health and widowhood, neither of which were associated with moves to regular housing in the first analysis, were moderated by the home characteristics in our second analyses: people who were widowed or experienced a decline in health moved to other regular housing if their old home was not fitted with special adaptations or if the entrance was not on the ground floor. Here we find an echo of Litwak and Longino's comfort move: people do not move closer to their children, but we do see that events associated with the onset of old age trigger a move to housing that may be better suited to future needs.

In conclusion, we have found partial support for the life course framework developed by Litwak and Longino (1987). Each of the life events studied - retirement, empty nest, widowhood and a decline in health - triggered specific moves. There is, however, no indication of a specific trajectory of moves associated with consecutive life events. The motives Litwak and Longino have ascribed to the various moves, which are related to leisure and care from children or professionals, cannot be replicated either. Although we did not specifically inquire into the motives for moving, the observed patterns deviated from Litwak and Longino's life course framework on many points. It is obvious that moving distances play a different role in the Netherlands than the USA. The opportunities and restraints offered by the local context can also be an important condition moderating the effects of life events on specific moves.

The proximity of children, either inside or outside the household, is not a decisive factor in residential choices. Only the major effects were visible in our sometimes small samples. A theoretical consideration is also that the role of children in most migration and other studies is reduced to their actual or possible role as caregivers (Silverstein \& Angelelli 1998; Stoller \& Longino 2001). In addition to the social advantages, having children nearby is likely to entail the psychological benefits of grandchildren in the vicinity (Oswald \& Rowles 2006). Since the distance to children as a reason not to move out of the neighborhood is left out of consideration altogether in most previous studies, we believe the role of children is underestimated in these studies. 
International Journal of Ageing and Later Life

As to our second research question, the accumulation of triggers and conditions, as suggested in the life course framework of residential mobility developed by Mulder and Hooimeijer (1999), is a valuable adjustment to the theoretical framework. As noted above, the impact of specific life events often depends on the presence of conditions. In particular, the effect of a decline in health on various types of moves was moderated by other conditions that were largely related to the availability of care and support.

The small number of movers and the relatively low frequency of cooccurrence of some events limit our analyses. This means our results can only be interpreted in an exploratory manner. The actual impact of events on residential moves may be underestimated. We measured events and moves in the same observation period and thus missed the longer-term effects of an event. It can be several years between the first idea of moving after an event such as widowhood and the actual move. We also had no observations on older adults who were institutionalized or deceased before the second observation.

Regardless of the possible underestimates, the scarcity of cases in an otherwise fairly large and representative sample of older adults keeps us from drawing up a normative account of moves in relation to specific events and conditions. As the model of Mulder and Hooimeijer (1999) also shows, there is no single path leading from a life event to a specific residential outcome. Important life changes may serve as reasons for moving, but the actual move depends on other events and conditions as well.

Focusing on the life course has two important advantages over more geographical models, such as the push and pull factor model applied by Haas and Serow (1993). First, it is analytically difficult to distinguish factors that push and pull at the individual level. Does a lack of adaptations push an individual out of the house? Is the presence of adaptations in a new home a pull factor that makes the individual move? What would the individual have done if a suitable new home had not been available? The same argument could be made about triggers and conditions, since these concepts do not guide empirical classification either. But unlike push and pull factors, triggers and conditions do help analyze how various factors may lead to specific residential changes. Second and more substantively, 
push and pull factors are mainly focused on housing and area characteristics. The life course framework focuses, however, on how specific events and conditions affect individual choices in a social and spatial context. The more complex model developed by Mulder and Hooimeijer (1999) has the extra advantage of analyzing joint effects of various events and conditions, which makes it more valid than most simpler models.

There are also certain limitations to our approach. We limited ourselves to objective factors and triggers outside the person. We were unable to analyze the actual decision-making process leading up to residential relocation. Personal appraisals, for example, are important in how specific events generate a residential move (Oswald \& Rowles 2006; Rowles \& Watkins 2003). Where people live is linked in many ways to how they live and experience life, and a decision to move also touches upon many psychological areas. A fuller understanding of late-life relocation would be greatly enhanced by a combination of sociological and psychological approaches. A life course model could serve as a framework, since it would allow for the incorporation of subjective triggers and conditions.

\section{Acknowledgements}

This study is based on data collected in the context of the "Longitudinal Aging Study Amsterdam", a program conducted at VU University Amsterdam and largely funded by the Ministry of Health, Welfare and Sports.

\section{Corresponding Author}

Brigitte Bloem, VU University Amsterdam, Department of Sociology, De Boelelaan 1081, NL-1081 HV Amsterdam, The Netherlands, Email: ba.bloem@fsw.vu.nl

\section{References}

Broese van Groenou, M. I. \& van Tilburg, T. G. (1997). Changes in the support networks of older adults in the Netherlands. Journal of CrossCultural Gerontology 12(1): 23-44. 
International Journal of Ageing and Later Life

Census, Office of National Statistics. (n.d.). Figure 10.8 Owner occupied dwellings, EU comparison, 2000. Available on http://www.statistics. gov.uk/STATBASE/ssdataset.asp?vlnk $=7326 \& M o r e=Y$ (Accessed: March 14, 2007).

Census, Office of National Statistics. (2001). Table KS 24 migration. Available on http://www.statistics.gov.uk/StatBase/ssdataset.asp?vl $\mathrm{nk}=7556 \&$ More $=\mathrm{Y}$ (Accessed: March 14, 2007).

Clark, W. A. V. \& Huang, Y. Q. (2003). The life course and residential mobility in British housing markets. Environment and Planning A 35(2): 323-339.

Deeg, D. J. H., Knipscheer, C. P. M. \& van Tilburg, W. (1993). Autonomy and Well-Being in the Aging Population: Concepts and Design of the Longitudinal Aging Study Amsterdam. Bunnik, The Netherlands: NIG.

den Dulk, C. J., van de Stadt, H. \& Vliegen, J. M. (1992). Een nieuwe maatstaf voor stedelijkheid: De omgevingsadressendichtheid [A new measure of urbanization: The address density of the surrounding area]. Maandstatistiek van de Bevolking 40(July): 14-27.

de Jong, G. F., Wilmoth, J. M., Angel, J. L. \& Cornwell, G. T. (1995). Motive and the geographic mobility of very old Americans. Journal of Gerontology 50B(6): S395-404.

Elder, G. H., Jr. (1985). Life Course Dynamics. Ithaca, NY: Cornell University Press.

Fokkema, C. M. (1996). Residential Moving Behaviour of the Elderly: An Explanatory Analysis for the Netherlands. Amsterdam, The Netherlands: Thesis Publishers.

Folstein, M. F., Folstein, S. E. \& McHugh, P. R. (1975). 'Mini-Mental State': A practical method for grading the cognitive state of patients for the clinician. Journal of Psychiatric Research 12(3): 189-198.

Freedman, V. A. (1996). Family structure and the risk of nursing home admission. Journal of Gerontology 51B(2): S61-69.

Haas, W. H. \& Serow, W. J. (1993). Amenity retirement migration process: A model and preliminary evidence. The Gerontologist 33(2): 212-220.

Knipscheer, C. P. M., de Jong Gierveld, J., van Tilburg, T. G. \& Dykstra, P. A. (1995). Living Arrangements and Social Networks of Older Adults. Amsterdam, The Netherlands: VU University Press. 
Litwak, E. \& Longino, C. F., Jr. (1987). Migration patterns among the elderly: A developmental perspective. The Gerontologist 27(3): 266-272.

Mulder, C. H. \& Hooimeijer, P. (1999). Residential relocations in the life course. In L. J. G. Wissen \& P. A. Dykstra (eds.) Population Issues: An Interdisciplinary Focus (pp. 159-178). New York: Kluwer.

Oswald, F. \& Rowles, G. D. (2006). Beyond the relocation trauma in old age: New trends in today's elders' residential decisions. In H.-W. Wahl, C. Tesch-Römer \& A. Hoff (eds.) New Dynamics in Old Age: Environironmental and Societal Perspectives (pp. 127-152). Amityville, NY: Baywood.

Pot, A. M., Deeg, D. J. H. \& Knipscheer, C. P. M. (2001). Institutionalisation of demented elderly: The role of caregiver characteristics. International Journal of Geriatric Psychiatry 16(3): 273-280.

Rowles, G. D. \& Watkins, J. F. (2003). History, habit, heart and hearth: On making spaces into places. In K. W. Schaie, H.-W. Wahl, H. Mollenkopf \& F. Oswald (eds.) Aging Independently: Living Arrangements and Mobility (pp. 77-96). New York: Springer.

Schachter, J. P. (2001). Why People Move: Exploring the Current Population Survey March 2000 (Current Population Reports). Washington, DC: U.S. Census Bureau.

Silverstein, M. \& Angelelli, J. J. (1998). Older parents' expectations of moving closer to children. Journal of Gerontology 53B(3): S153-163.

Statistics Netherlands. (2007). Binnen- en tussen gemeenten verhuisde personen: Regionaal [Persons Who Moved Within and Between Municipalities Classified by Region]. Voorburg, The Netherlands: CBS.

Stoller, E. P. \& Longino, C. F., Jr. (2001). 'Going home' or 'leaving home'? The impact of person and place ties on anticipated counterstream migration. The Gerontologist 41(1): 96-102.

Thissen, J. F. C. M. (1995). Bewoners en nederzettingen in Zeeland: Op weg naar een mieuwe verscheidenheid [Residents and Settlements in Zeeland: Toward a New Diversity]. Amsterdam/Utrecht: Netherlands Geographical Studies.

U.S. Census Bureau. (2000). Profile of General Demographic Characteristics for the United States: 2000. Washington, DC: Government Printing Office. 
International Journal of Ageing and Later Life

U.S. Census Bureau. (2006). Table 1. General Mobility, by Region, Sex, and Age: 2004-2005. Available on http://www.census.gov/population/ www/socdemo/migrate/cps2005.html (Accessed: June 22, 2007).

van der Molen, F. (1993). Woongedrag en huisvesting van ouderen [Residential Behaviour and Housing of Older People]. Groningen, The Netherlands: Wolters-Noordhoff.

Walters, W. H. (2002). Later-life migration in the United States: A review of recent research. Journal of Planning Literature 17(1): 37-66.

Warnes, A. M., Friedrich, K., Kellaher, L. \& Torres, S. (2004). The diversity and welfare of older migrants in Europe. Ageing \& Society 24(3): 307326.

Woningbehoefte Onderzoek (WBO). [Research on Housing Demands]. 2002. The Hague, The Netherlands: Ministry of Public Housing, City Planning and Environmental Management. 